\title{
VIABILIDADE ECONÔMICA DA AGROINDÚSTRIA FAMILIAR RURAL DE FRUTAS NA ZONA DA MATA MINEIRA ${ }^{1}$
}

\author{
Renata Couto Moreira ${ }^{2}$ \\ Brício dos Santos Reis ${ }^{3}$ \\ Vágner Ferraz Souza \\ Roberta Fialho \\ Cristiana Vieira Leocádio Rigueira ${ }^{6}$
}

Resumo - A agroindústria familiar rural visa, sobretudo, a produção de valor de troca que se realiza na comercialização. Partindo do pressuposto de que existe um importante gargalo entre a produção agrícola e o seu escoamento, o artigo traz uma análise da viabilidade econômica da agroindústria familiar rural, enfocando como estudo de caso uma agroindústria típica de doces de frutas na região da Zona da Mata mineira. Por meio da elaboração do Fluxo de Caixa do projeto, foram realizadas uma análise de sensibilidade e uma análise de risco pelo método de simulação de Monte Carlo. Os resultados encontrados foram favoráveis ao estímulo à implantação em maior escala, via políticas públicas, de projetos como o estudado, como uma proposta de desenvolvimento regional.

Palavras-chave: análise de risco, agricultura familiar, agroindústria de frutas.

\section{Introdução}

A agroindústria familiar rural vem sendo proposta como uma forma de organização em que a família produz e processa parte de sua produção agropecuária, visando sobretudo a produção de valor de troca na

\footnotetext{
Recebido em: 30/03/2007 Aceito em: 19/06/2007

2 Doutoranda em Economia Aplicada pelo Departamento de Economia Rural da UFV. E-mail: renatacm@dcc.ufla.br

3 Professor do Departamento de Economia Rural da UFV. E-mail: bricio@ufv.br

4 Mestrando em Ciência e Tecnologia de Alimentos pelo Departamento de Tecnologia de Alimentos da UFV. E-mail: vagnerfs@ hotmail.com

5 Mestre em Economia Aplicada pelo Departamento de Economia Rural da UFV. E-mail: fialhoroberta@yahoo.com.br

6 Mestranda em Economia Aplicada pelo Departamento de Economia Rural da UFV.

E-mail: crisvieirarigueira@yahoo.com.br
} 
comercialização. Sua localização é caracterizada no meio rural, podendo utilizar máquinas/equipamentos em escalas menores. A procedência da matéria-prima deve ser própria em sua maior parte (ou de vizinhos), os processos artesanais, próprios, assim como a mão-obra, da família, podendo ainda vir a ser um empreendimento associativo, reunindo uma ou várias famílias, aparentadas ou não (Mior, 2005). A abordagem, neste trabalho, parte do pressuposto de que há um importante gargalo entre a produção e o escoamento, expressando-se através dos problemas de armazenamento, das perdas na produção e da inexistência de canais de comercialização com fluxo permanente. Nesse contexto, o objetivo foi estudar a viabilidade econômica da industrialização de parte da produção agrícola de agricultores familiares, utilizando como estudo de caso uma agroindústria típica de doces de frutas na região da Zona da Mata mineira.

Em julho de 2004, um trabalho de capacitação no município de São Miguel do Anta teve a finalidade de levar ao município uma rede de microagroindústrias (Perez, 2004). O programa contou com o apoio do SENAR (Serviço Nacional de Aprendizagem Rural) e do Departamento de Economia Rural da Universidade Federal de Viçosa (UFV). Dentre os projetos que obtiveram os recursos, destaca-se um projeto piloto de agroindústria de goiabada cascão. Como a proprietária já havia feito um curso de produção de doces pela Emater, já revendia goiabada cascão para os mercados da região e comercializava sua produção de goiabas in natura com uma agroindústria de Ubá a $\mathrm{R} \$ 0,50$ o quilo, assumindo todos os custos de transporte, optou-se pela elaboração de um projeto de empréstimo para construção de um galpão e aquisição de equipamentos para uma pequena agroindústria de doces. $\mathrm{O}$ estudo se propôs a oferecer dimensões econômicas e financeiras, que envolveriam a escolha dessa alternativa de atuação aos órgãos promotores de políticas públicas, como proposta de desenvolvimento regional.

Como metodologia, foram implementadas abordagens de Fluxo de Caixa e Análise de Projetos sob Condições de Risco. O artigo introduz os conceitos sobre agricultura familiar e agroindústria na seção 2 . A seção 3 traz uma análise dos mercados de insumos e produtos da atividade na 
Renata Couto Moreira, Brício dos Santos Reis, Vágner Ferraz Souza, Roberta Fialho \& Cristiana Vieira Leocádio Rigueira

região estudada. Os modelos teóricos e métodos envolvidos são apresentados na seção 4 . Na seção 5, apresenta-se um estudo de viabilidade econômica do projeto de agroindústria de goiabada cascão do município de São Miguel do Anta. A seção 6 encerra o presente artigo, com algumas considerações finais.

\section{Agricultura Familiar e Agroindústria}

A agricultura familiar, segundo o Ministério do Desenvolvimento Agrário (MDA), constitui-se de propriedades de até quatro módulos rurais, definidos segundo regiões, em tabelas disponíveis pelo próprio ministério, sendo $80 \%$ da renda familiar proveniente da atividade rural. Além disso, a residência deve ser na própria propriedade ou em aglomerados rurais próximos, devendo-se manter no máximo dois empregados permanentes. Seguindo essa definição, o Censo Agropecuário de 1995/1996, último realizado pelo Instituto Brasileiro de Geografia e Estatística (IBGE) antes da elaboração deste trabalho, mostrou que a agricultura familiar representava quase $40 \%$ da riqueza gerada no setor agrícola, o que equivalia a 18 bilhões de reais; $77 \%$ dos estabelecimentos rurais, equivalendo a 383 mil propriedades rurais, ocupava apenas $30 \%$ da área total cultivada. Segundo dados do PRONAF (www.pronaf.gov.br), em 2003 o valor bruto da produção agropecuária proveniente da agricultura familiar representou cerca de 57 bilhões de reais. Pelas estatísticas do Banco Nacional de Desenvolvimento Econômico e Social (BNDES) de 1999, o setor é responsável pela geração de empregos de 37,1\% das pessoas ocupadas no Brasil; de cada 10 trabalhadores rurais, oito estão ocupados em atividades familiares. Com isso, destaca-se a expressiva participação da agricultura familiar na economia brasileira, justificando investimentos em estudos e pesquisas na área.

Segundo Zamberlam (1994), os agricultores familiares têm normalmente alternativas desfavoráveis de comercialização. Em regra, a possibilidade a que têm acesso é comercializar sua produção com grupos oligopolizados, sendo os preços fixados unilateralmente. As alternativas de comercializar 
via esquema tradicional (feiras, pequenos mercados, de casa em casa) - em que o produtor tem maior poder na definição do preço final de seus produtos — ou então iniciar um processo novo — dentro da dinâmica da "comercialização direta" com grupo de trabalhadores urbanos organizados, em que juntos definem as regras - esbarram nas dificuldades de conservação in natura de tais produtos e na informalidade, irregularidade e dificuldade de organização de tais mercados.

O complexo rural e suas formas de agregação tëm o seguinte perfil: agregado I, que produz insumos (sementes e adubos) e oferece crédito, e infra-estrutura; agregado II, que planta, colhe, cria, engorda etc.; e agregado III, que comercializa, industrializa e detém as estruturas de armazenamento. Pela definição clássica, os agregados I e III são oligopólios que aparecem como grandes agroindústrias, grandes cooperativas de comercialização, bancos, entre outros, os quais se apropriam de grande parte do lucro gerado pelo agregado II, integrado pelos agricultores. De acordo com Zamberlam (1994), quando um agricultor investe no agregado II, o retorno se dá na seguinte proporção: $23 \%$ para o agregado I, $66 \%$ para o agregado III e apenas $11 \%$ para o agregado II. Nessa dinâmica capitalista, a viabilidade da unidade agrícola familiar fica comprometida, sendo sugeridos grupos de cooperação e industrialização agrícola como alternativa para ampliar a renda dos agricultores familiares.

\section{Análise dos mercados de insumos e produtos: a agroindústria de frutas na Zona da Mata mineira (ZMM)}

A região da ZMM possui o maior parque industrial de processamento de frutas em Minas Gerais. Segundo dados da Empresa de Assistência Técnica e Extensão Rural do Estado de Minas Gerais (Emater-MG) de dezembro/2002, a estimativa total do déficit de frutas para atender apenas o consumo in natura e as agroindústrias já implantadas na região era de 49.779 t, correspondendo a 4.171 ha de plantio. Tomando a produção de 
Renata Couto Moreira, Brício dos Santos Reis, Vágner Ferraz Souza, Roberta Fialho \& Cristiana Vieira Leocádio Rigueira

goiabas como exemplo, a área em formação de goibeiras era de 65 ha; a área em produção era de 194 ha; a produtividade era estimada em $12 \mathrm{~kg}$ / ha/mês; e a produção girava em torno de 2.043 t de goiabas. O déficit, no caso específico, girava em torno de 18.017 t, correspondendo a 1.438 ha.

O relevo, que ocupa $87 \%$ da área da Zona da Mata mineira, é montanhoso e o clima caracteriza-se por um período seco durante o inverno, com temperaturas médias fortemente influenciadas pela ampla variação da altitude (de 150 a $1.300 \mathrm{~m}$ ). O zoneamento agroclimático da região favorece o cultivo de plantas de clima tropical e temperado. A estrutura fundiária das propriedades rurais é caracterizada como pequena ou média. As propriedades com 10 a 200 ha ocupam 66\% da área total (Moura et al., 2005). Em toda a região existe grande disponibilidade de mão-deobra e de terras de antigos produtores de cana- de-açúcar, que deixaram de produzir com o fechamento das usinas (Silva, 2001).

As produções agrícolas das próprias indústrias ainda são muito pouco expressivas no Brasil. Os fruticultores, na maioria das vezes, entregam os excedentes de produção a baixos preços durante os picos de safra, o que demonstra a falta de articulação deles entre si e com a indústria de frutas (Gayet, 1998). A caracterização do padrão locacional e a estrutura de mercado da agroindústria frutícola na ZMM, segundo diagnóstico realizado por Silva (2001), apesar da inexistência de uma fruticultura bem estabelecida, se justificam principalmente pela proximidade e facilidade de acesso aos principais mercados consumidores, como Rio de Janeiro, Belo Horizonte, Vitória e São Paulo, o que superou as dificuldades encontradas de abastecimento de frutas e da má conservação das rodovias.

Quanto ao porte, há diversidade muito grande e clara divisão das empresas que processam frutas. De um lado estão as grandes agroindústrias e cooperativas agrícolas, fabricantes de sucos e polpas, e de outro um enorme contingente de micro e pequenas empresas fabricantes de doces. Foi estimada em 2002 pela Emater-MG a existência de aproximadamente 
2.700 micro e pequenas agroindústrias, entre as quais predomina a fabricação de doces em massa, em calda e compotas. Destas, destacouse o sucesso da "goiabada cascão", produzida de forma artesanal, com grande aceitação comercial e, pelas estimativas da Emater, associada com a geração de aproximadamente 10.000 postos de trabalho direto e indireto. Esse fato, aliado ao crescimento dos mercados para frutas processadas, oferece excelente oportunidade para o fomento à agroindustrialização como um eixo de uma política sistêmica, visando melhorias nas condições de vida dos agricultores familiares e o desenvolvimento da fruticultura na região. No entanto, para expansão da fruticultura em maior escala, pelo diagnóstico apresentado por Silva (2001), são necessários, principalmente, ampliação do acesso a financiamentos apropriados, investimentos em infra-estrutura e concessão de assistência técnica adequada.

\section{Metodologia}

A análise da viabilidade financeira foi realizada em duas etapas, com a primeira delas consistindo na construção dos fluxos de caixa, que, uma vez obtidos, possibilitaram, na segunda etapa, o cálculo dos indicadores de rentabilidade da atividade considerada sob condições de risco.

\subsection{A Abordagem do Fluxo de Caixa na Avaliação de Projetos de Investimento}

Ao estudar projetos de investimento, devem-se considerar as consequiências futuras de decisões tomadas no presente. Por definição, qualquer investimento de capital implica certo dispêndio de dinheiro em bens duráveis (bens de capital) destinados a produzir outros bens durante certo período de tempo determinado no futuro. Em princípio, a análise de investimentos em bens duráveis (projetos) consiste em um tipo especial de orçamento. Seu diferencial se dá pelo fato de considerar o fator tempo explicitamente, pela inclusão da variação do valor do dinheiro no tempo 
Renata Couto Moreira, Brício dos Santos Reis, Vágner Ferraz Souza, Roberta Fialho \& Cristiana Vieira Leocádio Rigueira

na formação dos fluxos de dinheiro envolvidos no projeto, ou fluxo de caixa. Esses fluxos são formados por fluxos de entrada (receitas efetivas) e fluxos de saída (dispêndios efetivos), cujo diferencial é denominado fluxo líquido (Noronha, 1987). Sua formação só é possível se todas as especificações técnicas de recursos necessários, bem como de produtos, forem conhecidas. O estudo dos mercados de insumos e produtos é responsável pela determinação dos preços apropriados a cada tipo de análise. Tanto as quantidades físicas quanto os preços são projeções feitas a partir da data de início ao final do horizonte considerado no projeto. Assim, cada projeto é visto como uma alternativa cujo mérito é julgado em função das demais alternativas existentes.

No caso, como se trata de um projeto rural, todos os valores de insumos e produtos que formaram os fluxos de caixa foram calculados aos preços no próprio estabelecimento e considerados constantes como critério para projeção dos fluxos de caixa. A quantidade produzida pela agroindústria também seguiu esse critério, levando a uma receita constante, caso em que a unidade operaria até o fim do horizonte nas mesmas condições do início.

\subsection{A Escolha dos Indicadores}

Foram utilizados como indicadores de resultado econômico o Valor Presente Líquido (VPL) e a Taxa Interna de Retorno (TIR), que consideram o efeito do tempo sobre os valores monetários, e o Período de Payback (PB), que não o considera.

O valor presente líquido (VPL) consiste em transferir para o instante atual todas as variações de caixa esperadas, descontá-las a uma determinada taxa de juros e somá-las algebricamente, como na Equação (1).

$$
V P L=-I+\sum_{t=1}^{n} \frac{F C_{t}}{(1+K)^{t}}
$$


em que: I é o investimento de capital na data zero; FCt representa o retorno na data t do fluxo de caixa; $\mathrm{n}$ é o prazo de análise do projeto; e $\mathrm{k}$ é a taxa mínima para realizar o investimento.

A taxa interna de retorno (TIR) é a taxa que torna igual a zero o VPL do fluxo de caixa do investimento. É uma taxa que torna o valor presente dos lucros futuros equivalente ao dos gastos realizados com o projeto, caracterizando a taxa de remuneração do capital investido, e pode ser calculada usando a Equação (2).

$$
0=-I+\sum_{t=1}^{n} \frac{F C_{t}}{(1+T I R)^{t}}
$$

O período de Payback representa o prazo necessário para recuperação do capital investido, segundo Gitman (1997). Este serve como parâmetro de liquidez (quanto menor, maior a liquidez do projeto) e de risco (quanto menor, menor o risco do projeto). Esse método apresenta, no entanto, a desvantagem de não considerar o valor do dinheiro no tempo.

\subsection{Taxa de Desconto Utilizada}

Do ponto de vista econômico, a taxa de desconto, ou custo de oportunidade do capital, ou taxa mínima de atratividade, é dada pela taxa de crescimento no tempo de seu melhor uso alternativo. Tanto faz se é capital próprio ou de terceiros, ou se está na forma de bens físicos, papel negociável ou moeda. Seu cálculo, no presente trabalho, foi efetuado por meio de uma média ponderada entre o custo do financiamento (taxa de juros cobrada) e o custo do capital próprio. Para este, foi assumido um valor de $10 \%$ a.a., por estar próximo, apesar de superestimar, ao rendimento da caderneta de poupança nos últimos anos $(9,17 \%$ a.a. para 2005 e 8,22\% a.a. para 2006, como pode ser visto em www.ipeadata.gov.br). Os pesos de ponderação foram as razões entre o valor de cada um e o valor do capital total. 
Renata Couto Moreira, Brício dos Santos Reis, Vágner Ferraz Souza, Roberta Fialho \& Cristiana Vieira Leocádio Rigueira

Em novembro de 2004, a atividade foi contemplada com um empréstimo no valor de $\mathrm{R} \$ 6.000,00$, e o projeto, devido a alguns problemas com o clima e a mão-de-obra, só pôde ser concluído em setembro de 2005, começando a operar em março de 2006, em razão do atraso da visita e do licenciamento dos órgãos de inspeção sanitária. O crédito e a taxa resultante calculada podem ser visualizados na Tabela 1 . O crédito adquirido corresponde ao Pronaf Mulher nível C, que confere o direito a pagar o valor do empréstimo em cinco prestações anuais, sem carência, no valor de $20 \%$ do principal. A taxa de juros cobrada é de $4 \%$ ao ano, possuindo um bônus de adimplência de $25 \%$ sobre ela. Além disso, no caso de pagamento em dia, há ainda um rebate de $\mathrm{R} \$ 700,00$, a ser distribuído igualmente entre as parcelas. $\mathrm{O}$ cálculo final do custo do financiamento foi de $3 \%$ a.a., ressaltando-se nesse aspecto o papel do bônus de adimplência na redução deste custo.

Tabela 1 - Financiamento Pronaf-Mulher e cálculo do custo do capital, em R\$

\begin{tabular}{|c|c|c|c|c|c|}
\hline Financiamento & Principal & Saldo devedor & Amortização* & Juros** & Prestação \\
\hline 0 (nov./2004) & 6000,00 & & & & \\
\hline 1 (out./2005) & & 4800,00 & $-1211,20$ & $-180,00$ & $-1391,20$ \\
\hline 2 (out./2006) & & 3600,00 & $-1211,20$ & $-144,00$ & $-1355,20$ \\
\hline 3 (out./2007) & & 2400,00 & $-1211,20$ & $-108,00$ & $-1319,20$ \\
\hline 4 (out./2008) & & 1200,00 & $-1211,20$ & $-72,00$ & $-1283,20$ \\
\hline 5(out./2009) & & 0,00 & $-1211,20$ & $-36,00$ & $-1247,20$ \\
\hline Total & & & $-6056,00$ & $-540,00$ & $-6596,00$ \\
\hline & \multicolumn{3}{|c|}{ Valor $(\mathrm{R} \$)$} & \multicolumn{2}{|c|}{ Custo (\% ao ano) } \\
\hline Financiamento & & \multicolumn{2}{|l|}{6000,00} & \multicolumn{2}{|c|}{3} \\
\hline Capital P (próprio) & & \multicolumn{2}{|l|}{3000,00} & \multicolumn{2}{|l|}{10} \\
\hline Capital T (total)*** & & \multicolumn{2}{|l|}{9000,00} & \multicolumn{2}{|l|}{5,33} \\
\hline
\end{tabular}

*inclui os valores do seguro e do rebate ** inclui o bônus de $25 \%$ sobre a taxa de juro. Fonte de dados: preços na propriedade, valores em reais de maio de 2006

Graças à diversificação de atividades realizadas na unidade produtiva em questão, a primeira parcela do financiamento pôde ser paga com capital próprio, apesar de a agroindústria ainda não estar em operação. 


\subsection{Análise de Risco em Projetos de Investimento}

Ao aplicar os critérios de avaliação de projetos, as decisões são baseadas em projeções de preços, renda, tecnologia, condições de oferta e outras variáveis. Em muitos casos, existe um considerável grau de imprecisão nessa prática. Nesse sentido, segundo Noronha (1987), quando são desconhecidos os possíveis estados futuros de uma certa variável e suas respectivas probabilidades de ocorrência, verifica-se o que se pode denominar de incerteza. Alguns elementos variam, e essas variações podem afetar o orçamento. Há vários métodos para estimar a amplitude dos efeitos dessas variações na atividade.

Um método muito conhecido que foi usado é o de análise de sensibilidade, que consiste em medir a magnitude de possíveis alterações no resultado final devido a uma alteração prefixada em um ou mais fatores do projeto individualmente. De acordo com Buarque (1991), esse método permite avaliar a forma como as alterações de cada uma das variáveis do projeto podem influenciar a rentabilidade dos resultados esperados. Essa técnica, no entanto, não diz nada sobre o efeito combinado de mudanças em mais de uma variável em conjunto. Na prática, consiste na variação sistemática das variáveis para identificar as que exercem maior influência no projeto, pelo cálculo dos efeitos de variações percentuais destas sobre os indicadores financeiros selecionados - o VPL, no caso. A maior sensibilidade do projeto ao alterar uma variável-chave é relacionada a um maior grau de incerteza.

Outra técnica utilizada foi a simulação de Monte Carlo, que consiste em gerar informações supondo que os eventos ocorram de forma aleatória. Segundo Noronha (1987), ao se realizar a simulação de Monte Carlo, devem-se seguir os seguintes passos: identificar uma distribuição de probabilidade para cada uma das variáveis relevantes do fluxo de caixa identificadas na análise de sensibilidade; selecionar ao acaso um valor de cada variável, com auxílio de um gerador de números aleatórios; calcular o valor do indicador; e repetir o processo até que se obtenha confirmação adequada da distribuição de frequiência do indicador de 
Renata Couto Moreira, Brício dos Santos Reis, Vágner Ferraz Souza, Roberta Fialho \& Cristiana Vieira Leocádio Rigueira

escolha. Após as simulações, avalia-se o risco pela probabilidade acumulada de o projeto obter um retorno não desejado - no caso, um VPL negativo. Dependendo do perfil do empreendedor - averso, neutro ou propenso ao risco - , essa probabilidade de insucesso pode ser satisfatória ou não, subjetividade que reflete suas dificuldades de generalização. Neste trabalho, a simulação de Monte Carlo foi realizada com o uso do software @RISK (Palisade Corporation), com cálculo de 100 cenários possíveis, cujas distribuições de probabilidades de ocorrência das variáveis estocásticas foram aproximadas pela distribuição normal, com uso da função @ risknormal do programa.

\subsection{Fonte de Dados}

Todos os preços considerados foram coletados por meio de entrevistas realizadas em maio de 2006, para refletir o real potencial. Os resultados finais da análise referem-se, tão-somente, ao enfoque sob a "ótica empresarial e financeira". O Instituto de Desenvolvimento Industrial do Estado de Minas Gerais (INDI-MG) e a Federação de Agricultura do Estado de Minas Gerais (FAEMG) também foram consultados sobre o estabelecimento de um padrão estrutural para a agroindústria frutícola da região. O valor médio e a variância das variáveis estocásticas na análise de risco foram estabelecidos com base em comportamentos passados retirados dos censos do IBGE.

Foi realizada uma entrevista semi-estruturada, na qual foram disponibilizadas todas as informações sobre as compras realizadas dos insumos, as vendas e estoques de doces, desde o início da operação da agroindústria, os dados sobre o financiamento, sobre a produção das frutas, suas possibilidades de venda e a capacidade máxima de produção da agroindústria. Dessa forma, neste artigo é feita uma análise de viabilidade ex-post sob condições de risco para o projeto, dentro de um horizonte de 10 anos, a partir do início de operação da agroindústria, em março de 2006. 


\section{Resultados e Discussões}

\subsection{O fluxo de caixa do projeto}

Além dos critérios preestabelecidos, as projeções econômicas consideraram que os preços de mercado dos produtos $\left(\mathrm{P}_{\text {goiabadaM }}\right)$ se referem a preços nos mercados locais, e os preços particulares $\left(\mathrm{P}_{\text {goiabadaP }}\right)$ se referem a preços de venda diretamente na residência dos consumidores. Não há custos com a utilização da terra, pois esta é emprestada, sendo constituída por 2 hectares, possuindo 120 pés de goiaba com 10 anos de idade. A produção oriunda de 80 pés é destinada à agroindústria e o restante, à venda in natura no mercado da região. A produção máxima de doce foi limitada pela capacidade média de produção de goiaba por ano da propriedade: em torno de $70 \mathrm{~kg} /$ pé/ano. Para essa quantidade, basta o uso de três dias de trabalho na agroindústria, o que pode ser ampliado para os cinco dias úteis da semana com o aumento apenas dos insumos. A depreciação dos equipamentos é maior que 20 anos, não sendo necessários reinvestimentos num horizonte escolhido de 10 anos, dobro do prazo do financiamento. Os valores do investimento e das receitas líquidas são inferiores ao valor mínimo para cobrança de imposto de renda (IR). Optou-se, adotando ainda uma postura conservadora, por não considerar possíveis valores residuais. Como custo de oportunidade, a receita obtida pelas vendas in natura das goiabas para a agroindústria de Ubá foi considerada a melhor opção conseguida e, por isso, foi nomeada de Custo da Matéria-Prima (Custo MP). Na Tabela 2 encontra-se o fluxo de caixa resultante. 
Renata Couto Moreira, Brício dos Santos Reis, Vágner Ferraz Souza, Roberta Fialho \& Cristiana Vieira Leocádio Rigueira

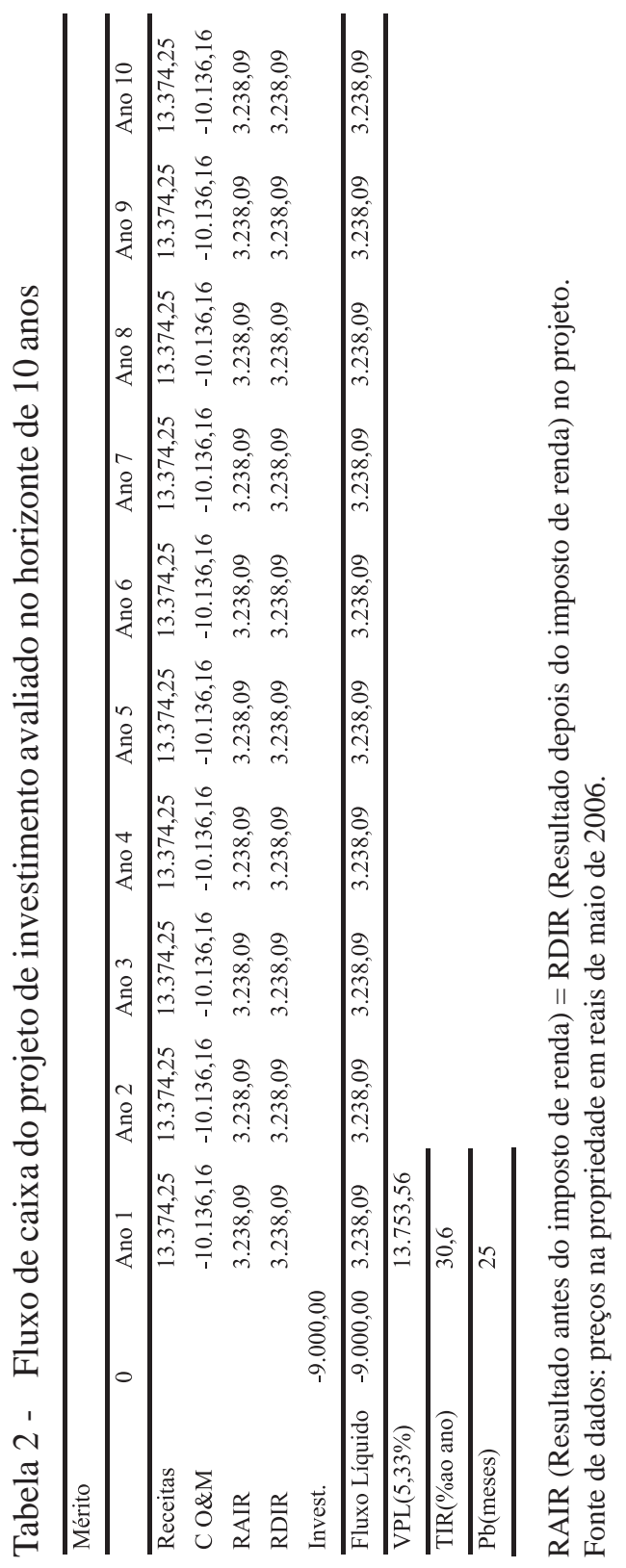


Os lucros econômicos obtidos no fluxo de caixa foram de $\mathrm{R} \$ 3.238,09$ por ano, além do valor da remuneração da atividade anterior $(\mathrm{R} \$ 640,00$ por ano), sendo cinco vezes superior a este, o que condiz com a teoria de apropriação de valores pelos diferentes agregados do complexo rural de Zamberlam (1994). Isso geraria uma renda média mensal em torno de $\mathrm{R} \$ 325,00$, como remuneração do trabalho na agroindústria. Na época da coleta de dados, que foi o cenário considerado nas estimativas futuras no horizonte do projeto, esse valor representava três dias de tempo livre semanal, ou seja, superior à remuneração diária, tendo como base o salário mínimo de março de 2006 ( $\mathrm{R} \$ 300,00$ mensais).

\subsection{Cálculo dos Indicadores}

Os indicadores de rentabilidade obtidos para produção do doce da goiaba foram de $\mathrm{R} \$ 13.753,56$ para o VPL, considerando taxa de desconto de $5,33 \%$; 30,6\% para a TIR; e dois anos e um mês para o período de payback. O VPL foi positivo, apontando para a viabilidade do projeto na análise de mérito. Seu valor está, porém, superestimado, pelo fato de o custo do capital considerado (5,33\% ao ano) ter sido relativamente baixo quando comparado às taxas da caderneta de poupança, por exemplo (disponíveis em http://www.ipeadata.gov.br). Com relação à TIR, a atividade também é recomendada, uma vez que o retorno do projeto é elevado se comparado ao valor da taxa mínima de atratividade. O período de payback é pequeno com relação ao tempo do financiamento de cinco anos, o que sinaliza para a liquidez do projeto antes da necessidade de quitar os investimentos, diminuindo, assim, os seus riscos.

Os custos associados ao projeto podem ser considerados baixos, tanto os custos fixos anuais $(\mathrm{R} \$ 2.804,10)$ quanto os variáveis anuais $(\mathrm{R} \$ 7.332,06)$. Isso se deve ao baixo grau de especialização dos insumos fixos, como colheres de pau, facas e panelas, podendo ser reaproveitados caso a atividade se torne inviável, assim como dos insumos variáveis, cujo maior custo está associado ao custo do açúcar ( $\mathrm{R} \$ 3.396,00$ por ano), que é um insumo que pode ser comprado durante o processo produtivo e distribuído 
Renata Couto Moreira, Brício dos Santos Reis, Vágner Ferraz Souza, Roberta Fialho \& Cristiana Vieira Leocádio Rigueira

por todo o ano. $\mathrm{O}$ grau de perecibilidade das matérias-primas, por outro lado, é alto, o que compromete não somente a qualidade dos produtos, como também agrega custos relevantes de desperdícios. O transporte da produção em barras de doce, no entanto, facilita o manuseio, comparado com as dificuldades encontradas com a fruta in natura, além de agregar mais valor a um volume menor no transporte.

\subsection{Análise de sensibilidade e de risco}

A produção anual da agroindústria foi a variável de maior impacto sobre o VPL (0,768 unidade a cada variação de $1 \%$ na produção). Em seguida vêm os preços de venda da goiabada $(0,352$ unidade a cada variação no preço particular e 0,281 no preço de mercado), o preço do açúcar ($0,236)$, o custo da matéria-prima (MP) $(-0,226)$ e o preço das etiquetas $(-0,122)$, em ordem de importância. Isso significa que, a cada ponto percentual que a agroindústria aumenta no seu produto, o VPL aumenta em média 77 pontos percentuais. Esse resultado é positivo, já que a capacidade máxima da agroindústria é superior à considerada na avaliação, podendo-se expandir o produto sem necessidade de investimentos adicionais. É importante ressaltar que as variáveis do lado das receitas foram mais sensíveis que as do lado dos custos sobre a viabilidade do projeto.

Quanto ao preço do açúcar, caso se eleve a ponto de inviabilizar a operação da agroindústria, os prejuízos seriam dissolvidos, reduzindo os riscos envolvidos com relação a essa variável. A variação percentual do VPL com a variação percentual do custo da MP indicou que, a cada aumento de $1 \%$ no valor pago pelas goiabas in natura pelas agroindústrias já existentes na região, o VPL diminui de 23 p.p. Por fim, os preços pagos pelas etiquetas estão acima dos preços de mercado, devido ao fato de que as etiquetas foram confeccionadas em pouca quantidade, de forma artesanal - custo este que pode ser reduzido pela confecção destas em maiores quantidades em uma das gráficas da região, que podem oferecer o serviço a preço mais baixo. Os resultados das simulações do projeto sob condições de risco podem ser visualizados na Tabela 3 . 
REVISTA DE ECONOMIA E AGRONEGÓCIO, VOL.5, $N^{o} 2$

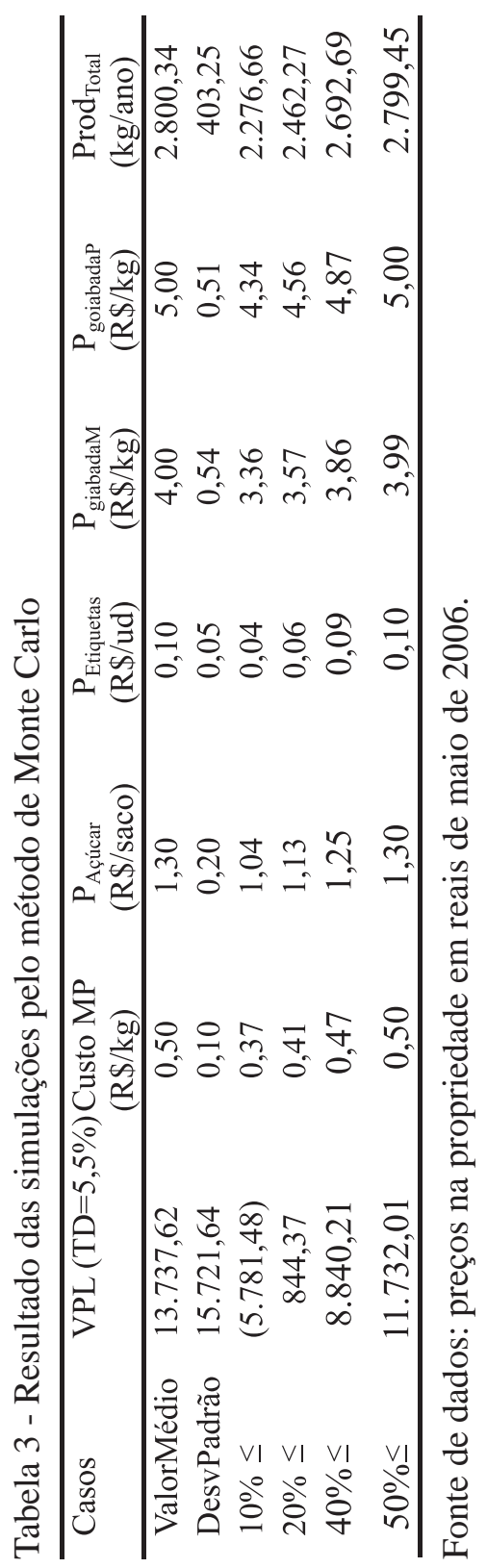


Renata Couto Moreira, Brício dos Santos Reis, Vágner Ferraz Souza, Roberta Fialho \& Cristiana Vieira Leocádio Rigueira

O valor médio do VPL foi de $\mathrm{R} \$ 13.737,62$, próximo ao obtido na análise sem risco, e seu desvio- padrão foi de $\mathrm{R} \$ 15.721,64$, valor alto se comparado ao valor médio. Portanto, o VPL, se calculado repetidas vezes em amostras fixas, em 95\% dos casos se encontrará no intervalo de confiança de $[-17.076,79 ; 30.828,15]$. Apesar de o intervalo de confiança calculado incluir valores negativos, a probabilidade de risco de inviabilidade do projeto (VPL <0) é inferior a $20 \%$, o que pode ser considerado baixo, em razão das características ressaltadas na análise de sensibilidade associadas à atividade. Aprofundando a análise, percebe-se que em 50\% dos casos ocorreram valores de VPL superiores a $\mathrm{R} \$ 11.732,00$, e em torno de $59 \%$ dos casos ocorreram valores superiores ao investimento inicial, de $\mathrm{R} \$ 9.000,00$, aspectos que contribuem de forma positiva na avaliação do risco.

\section{Considerações Finais}

A metodologia usada foi essencial para calcular a dimensão dos retornos da implementação de um projeto como o avaliado, e os resultados foram coerentes com a teoria, sugerindo que a implantação e operação da agroindústria trariam um retorno cinco vezes superior ao da atividade exercida anteriormente, a uma taxa de risco inferior a 20\% — satisfatória, considerando o baixo grau de especialização dos insumos. A avaliação de mérito foi positiva para a atividade, sendo a taxa de remuneração do capital investido em torno de três vezes a taxa mínima de atratividade considerada e o período de recuperação deste inferior à metade do tempo disponível para o pagamento do financiamento - indicativo de liquidez. Além de agregar valor às frutas, seriam reduzidos assim os desperdícios e as perdas oriundos dos processos de seleção e classificação, promovendo o aproveitamento dos excedentes de safra e a criação de empregos, atuando de forma significativa no aumento da renda familiar.

As dificuldades de formalização da atividade, como a falta de órgãos de fiscalização e assistência técnica no município, representam os maiores entraves enfrentados na condução da atividade, assim como a 
inadequação da legislação à realidade da agricultura familiar, aumentando excessivamente os custos de produção e comercialização e impondo barreiras sanitárias, trabalhistas, ambientais, tributárias, fiscais e previdenciárias. A associação com outros agricultores poderia agilizar os processos junto às autoridades políticas responsáveis, assim como viabilizar a compra de insumos mais baratos e a aquisição de melhores preços na venda dos doces, alternativa esta possível, visto que na região já existem muitas relações informais de cooperação agrícola, como empréstimos de terras a familiares, trocas de excedentes entre vizinhos e trocas de dias de trabalho. A situação crítica dos serviços públicos no meio rural e a descontinuidade dos planos de governo devido às disputas políticas ocorridas no município, no entanto, estabelecem grande dificuldade para o desenvolvimento da região.

Conclui-se que os impactos que o estímulo à implantação, em ampla escala, de projetos como o estudado, organizados e articulados entre si, como uma proposta de desenvolvimento da cadeia produtiva da fruticultura na região, podem trazer melhorias substanciais nas condições de vida da população em geral, e das famílias rurais em particular. Podem, também, refletir significativamente na desconcentração da renda, viabilizando a fixação dos trabalhadores rurais em suas próprias terras, com a apropriação por estes de uma maior parte do valor agregado aos produtos agrícolas, usando técnicas muitas vezes tradicionais e de baixo custo de processamento. 
Renata Couto Moreira, Brício dos Santos Reis, Vágner Ferraz Souza, Roberta Fialho \& Cristiana Vieira Leocádio Rigueira

\section{Referências}

BUARQUE, C. A incerteza para seleção de projetos. In: BUARQUE, C. (Ed.). Avaliação econômica de projetos. 8.ed. Rio de Janeiro: Campus, 1991.

GAYET, J. P. A agroindústria de frutas à parte do nosso negócio. Caderno de Recomendações, abr., 1998.

GITMAN, L.J. Princípios de administração financeira. 7.ed. São Paulo: HARBRA, 1997.

MIOR, L. C.. Agricultores familiares, agroindústrias e redes de desenvolvimento rural. Chapecó: Argos, 2005.

MOURA, A. D.; SILVA JÚNIOR, A. G.; VIEIRA, L. B. Agricultura familiar no agronegócio. Viçosa, MG: Pró-Reitoria de Extensão e Cultura-UFV, 2005.

NORONHA, J. F. Projetos agropecuários: administração financeira, orçamentária e viabilidade econômica. 2. ed. São Paulo, SP: Atlas, 1987.

PEREZ, R. . Relatório final: projeto agroindustrialização do município de São Miguel do Anta. Viçosa: Universidade Federal de Viçosa, 2004.

SILVA, C. A. B. da. Diagnóstico da cadeia agroindustrial de frutas selecionadas no Estado de Minas Gerais - Relatório Final. Viçosa: Contrato Funarbe / UFV - Sebrae-MG, 2001.

ZAMBERLAM, J. Reflexões sobre algumas estratégias para a viabilização econômica dos assentamentos". In: MEDEIROS, L. et al. (Ed.). Assentamentos rurais: uma visão multidisciplinar. São Paulo: UNESP, 1994. 
Abstract - The called Rural Familiar Agroindustry aims at, over all, the production of value of exchange which takes place in the commercialization. From the presuppose that exists an important pass between the agricultural production and its draining, the article brings an analysis of the economic viability of the rural familiar agroindustry, bringing as case study a typical agroindustry of candies of fruits in the Zona da Mata Mineira region. By the elaboration of the box flow of the project, a sensibility analysis and a risk analysis by the Mont Carlo simulation method were realized. The joined results were favorable to the stimulation to the implantation in a bigger scale, with public policies, of projects as the studied one, as a proposal of regional development.

Keywords: risk analysis, familiar agriculture, fruit agroindustry. 